\title{
The Importance of Metacommunication in Supervision
}

\section{Processes in Higher Education}

\author{
Rolf K. Baltzersen ${ }^{1,2}$ \\ ${ }^{1}$ Ontario Institute for Studies in Education, University of Toronto, Toronto, Canada \\ ${ }^{2}$ Faculty of Education, Østfold University College, Halden, Norway \\ Correspondence: Rolf K. Baltzersen, Østfold University College, 1757 Halden, Norway. E-mail: \\ rolf.k.baltzersen@hiof.no \\ Received: April 11, 2013 \\ Accepted: May 2, 2013 \\ Online Published: May 3, 2013 \\ doi:10.5430/ijhe.v2n2p128 \\ URL: http://dx.doi.org/10.5430/ijhe.v2n2p128
}

\begin{abstract}
In daily language use, we sometimes comment on the conversation with phrases such as "What do you mean by saying that?" or "That was nice of you to say." This communication about the communication is sometimes labeled as metacommunication. It can be used for many different purposes; for instance, to try and clarify or appraise something that has been said in a conversation. In higher education, a recent empirical study finds that discussions between the student and supervisor about the supervision process have a positive impact on the quality of the communication. Despite this, we know little about the specific metacommunicative mechanisms that may be of importance in supervision. One reason is that most definitions of the metacommunication concept are vague and inconsistent. The goal of this paper is therefore to review a broad range of research literature about metacommunication in an attempt to develop a more comprehensive and complex definition. These perspectives are then used to discuss what specific types of metacommunication might facilitate good supervision in higher education. It is suggested that one should distinguish between metacommunication as part of a transparent communication style and metacommunication about the collaboration period in supervision.
\end{abstract}

Keywords: Metacommunication, Supervision, Higher education, Communication, Mentoring

\section{The importance of metacommunication in supervision in higher education}

In daily language use, we sometimes comment on the conversation with phrases such as "What do you mean by saying that?" or "That was nice of you to say." We seem to use this kind of communication for several different purposes; for example, to clarify or appraise a communicative message. Bateson (1972) labeled this kind of communication as metacommunication and claimed it was essential for successful human communication. Using metacommunication may, in other words, be seen as a verbal tool that can improve communication. In higher education there is also an increasing interest in how one can facilitate good communication in different supervision processes. (Note 1) "Good" doctoral supervision is, for example, considered very important for successful research education programs (Walker, Golde, Jones, Bueschel \& Hutchings, 2008).

Supervision of students' written work in higher education is typically conducted at several different course levels. Past studies have primarily investigated the supervision of students' work with a PhD thesis (Sinclair, 2004; Deuchar, 2008; Lee, 2008; Sambrook, Stewart \& Roberts, 2008; Whitelock, Faulkner \& Miell, 2008; Halse \& Malfroy, 2010; McCallin \& Nayar, 2012; Wichmann-Hansen, Bach, Eika \& Mulvany, 2012). In comparison, there have been few studies of the supervision of bachelor and master theses (Dysthe, Samara \& Westrheim, 2006; Holmberg, 2006). Most of this research literature suggests that good communication between the supervisor and the student is vital. Nevertheless, the metacommunication concept seems to be seldom used.

One exception is Baltzersen (2008), who has investigated the impact of metacommunication in the supervision process in higher education in Norway. He reanalyzed the statistical database from the first national survey about supervision of graduate students (master level) in Norway (Falkfjell \& Smeby, 1999). (Note 2) Several of the questions in the survey could be related to the metacommunication concept, but they had not been analyzed statistically in great detail in the research report. By combining three of these selected variables, Baltzersen (2008) was able to create a new variable that could describe frequency of metacommunication (no metacommunication, 
early phase metacommunication and regular metacommunication) in the supervision process in a more differentiated way.

Table 1. Characteristics of the new variable that describe frequency of metacommunication

\begin{tabular}{|c|c|c|c|}
\hline & $\begin{array}{l}\text { No } \\
\text { meta-communic } \\
\text { ation }\end{array}$ & $\begin{array}{l}\text { Early-phase } \\
\text { meta-communicatio } \\
\mathrm{n}\end{array}$ & $\begin{array}{l}\text { Regular } \\
\text { meta-communication }\end{array}$ \\
\hline $\begin{array}{l}\text { Variable } 1 . \text { Have you and your supervisor } \\
\text { discussed the supervising process? } \\
\text { (Answer categories: Never, seldom and } \\
\text { regularly) }\end{array}$ & Never/Seldom & Never/Seldom & Regularly \\
\hline $\begin{array}{l}\text { Variable } 2 . \text { Have you and your supervisor } \\
\text { discussed or clarified the supervisor's role } \\
\text { and tasks in the supervising process? } \\
\text { (Answer categories: Yes and No) }\end{array}$ & No & Yes & Yes \\
\hline $\begin{array}{l}\text { Variable 3. Have you and your supervisor } \\
\text { discussed or clarified your role and tasks } \\
\text { in the supervising process? (Answer } \\
\text { categories: Yes and No) }\end{array}$ & No & Yes & Yes \\
\hline
\end{tabular}

By constructing this new variable Baltzersen (2008) was able to statistically locate early-phase metacommunication in the supervision process. Students in this group had discussed and clarified the roles of the supervisor and the student in the supervising process, but they had not discussed the supervision regularly. The statistical results from the survey showed that approximately one third $(29 \%)$ of the students had only participated in early-phase metacommunication. Slightly above half of the students $(59 \%)$ had not metacommunicated in the supervising process at all, while only $12 \%$ had done so regularly. Furthermore, results from the survey showed that the correlation between the frequency of metacommunication and the students' experience of the quality of the communication with the supervisor is strong ( 0.33 with Kendall's Tau-b).

Table 2. Percentage relationship between degree of metacommunication and experience of good communication with supervisor

\begin{tabular}{|c|c|c|}
\hline $\begin{array}{l}\text { Strongly agrees Agrees } \\
\text { that } \\
\text { communication } \\
\text { is good }\end{array}$ & $\begin{array}{l}\text { Both agrees and Disagrees } \\
\text { disagrees. }\end{array}$ & $\begin{array}{l}\text { Strongly } \\
\text { disagrees that } \\
\text { communication } \\
\text { is good. }\end{array}$ \\
\hline
\end{tabular}

\begin{tabular}{|c|c|c|c|c|c|c|}
\hline $\begin{array}{l}\text { No meta- } \\
\text { communication }\end{array}$ & 21 & 30 & 33 & 10 & 6 & $100 \%$ \\
\hline $\begin{array}{l}\text { Early-phase } \\
\text { meta- } \\
\text { communication }\end{array}$ & 37 & 42 & 17 & 4 & 1 & $100 \%$ \\
\hline $\begin{array}{l}\text { Regular meta- } \\
\text { communication }\end{array}$ & 65 & 27 & 8 & 0 & 0 & $100 \%$ \\
\hline Total & 31 & 33 & 26 & 7 & 4 & $100 \%$ \\
\hline
\end{tabular}

Table 2 shows that $65 \%$ of the students who regularly metacommunicate strongly agree that the communication with the supervisor is good. At the opposite end, only $21 \%$ of the students who have not metacommunicated strongly agree that the communication is good. One should also notice that none of the students who regularly metacommunicate think that the communication is bad. It seems as if metacommunication may decrease the amount of obstructive conflicts in the supervision. One could ask if there is some kind of spurious effect present here. For 
example, one might argue that it is not the metacommunication, but the frequency of the supervision that improves the quality of the communication. However, when controlling for this variable, Baltzersen (2008) finds that this is not the case.

These results indicate that metacommunication may have a substantial positive effect on the quality of communication in thesis supervision. The quantitative data suggest that when metacommunication is present, the student considers the supervising process as good. Still, this gives few substantial suggestions on how metacommunication may specifically influence communication in a positive way. It still remains unclear what kind of metacommunicative content may be important for different kinds of supervision in higher education. To try and locate these positive mechanisms as a first step, this study reviewed research literature that describes the metacommunication concept and how it may potentially influence different types of communication in a positive way. The goal is to use this knowledge to try and answer the following research question:

What kind of metacommunication is important to create good supervision in higher education?

To answer this question, the use of the metacommunication concept is reviewed from several different research areas beyond the field of higher education. This is considered necessary in order to understand the concept in a more comprehensive and complex way. In the concluding remarks, the importance of two types of metacommunication is discussed in relation to supervision in higher education.

\section{Background about the metacommunication concept}

\subsection{The origin of the metacommunication concept}

The prefix "meta-" can have different meanings, but in relation to the metacommunication concept, it is usually defined as "communication as communication" (Bateson, 1951: 209). The concept was originally introduced by Bateson (1951) who suggested that there existed different levels of abstraction in human communication. The concept was developed from detailed observation of play among animals. Through this work Bateson (1976) claimed that metacommunication is constantly defining the ongoing activity as "We are playing now." This particular frame constrains how animals interpret their behavior. Like the concrete frame in a picture which guides our perception of the motive, so does metacommunication frame the talk between people. Metacommunication or messages about frame (e.g. we are playing now) is usually not explicit. Instead people often unconsciously guess what kind of context they are part of (e.g. a sincere apology, a sexual proposal). This may also sometimes create misunderstandings. In such cases people can metacommunicate verbally with phrases such as "What do you mean by saying that?" We seem to use this kind of communication for several different purposes, for example to clarify or appraise a communicative message. Bateson (1972) claimed that these comments were essential for successful human communication.

Rossiter (1974) later divided the metacommunication concept into two separate types. The first type is similar to Bateson's original definition, which describes metacommunication as anything that contextualizes communication. Nonverbal communication is important, such as voice intensity, facial expression and body gestures. This communication can inform others about intentions and feelings and may either support or contradict the verbal message. The second type of metacommunication focuses on verbal comments about the communication. For example, this can be some kind of evaluation of the communication (Rossiter, 1974).

Wilmot (1980) later makes another distinction between relational and episodic metacommunication. Relational metacommunication is any comment about the relationship between the persons who are communicating with each other. This can be done in several different ways. For example, one can talk about the persons in the conversation (e.g. "You always complain.") the interaction itself (e.g. "Now we are having a nice time.") or one can give a relational definition ("We have never been good friends."). This kind of metacommunication will often influence how people see each other in the further conversation. Usually, it is implicit and remains unspoken. In such cases the nature of the relationship is interpreted from the non-verbal communication between the participants. On the other hand, episodic metacommunication refers to verbal comments that are made about an upcoming, ongoing or past communicative episode. This kind of metacommunication can either focus on the other person's acts or messages ("Why are you interrupting me?"), oneself ("I don't know if I am clear.") or the communicative episode itself ("This is an important meeting.") (Wilmot, 1980). While early applications of the concept focused primarily on non-verbal metacommunication, today there is an increased interest in the verbal aspects of metacommunication (Whitebread \& O’Sullivan, 2012). 


\subsection{Use of the metacommunication concept within different contexts}

According to Whitebread and O'Sullivan (2012), the metacommunication concept has received limited scientific attention. Nevertheless, a search for relevant papers in Google Scholar shows that the concept is used to a certain extent in some research areas. First, in research about social pretend play, there seems to be an increasing interest in verbal metacommunication (Doehring, 1993; Halliday-Scher, Urberg \& Kaplan-Estrin, 1995; Sawyer, 1997, 2003; Whitebread \& O'Sullivan, 2012). In this context, Whitebread and O'Sullivan (2012) make a distinction between explicit and implicit metacommunication. Explicit metacommunication is used to describe children when they take the role of the narrator rather than being their play character. Such "out-of-frame" strategies are usually verbal and often used in the beginning of the play in order to establish roles and relationships (e.g. "I want to be Dad and you can be Mom."). Oppositely, implicit metacommunication is used to describe children when they remain in character while they are metacommunicating. In these situations, both verbal and non-verbal behavior help to define the play frame, but it is not talked about explicitly. This is considered more effective once the play has started because there are fewer disruptions in the play. Whitebread and O'Sullivan (2012) also suggest that metacommunication can be described along a continuum from "within-frame" to "out-of-frame" with both types of metacommunication including non-verbal and verbal cues.

Within research on psychotherapy, metacommunication seems to be primarily used as a concept related to "talk about talk". For example, Kiesler (1988) describes metacommunication as the verbal exploration of the unfolding relationship between the therapist and client. This is considered a key feature of interpersonal and relational psychotherapies. Austin (2011) also suggests that metacommunication should be regarded as an important counseling "microskill." In the learning sciences, Dillenbourg and Traum (2006) use the metacommunication concept as one of four main content categories when they analyze interactions in multimodal collaborative problem solving. The concept is defined as utterances about the interaction itself. This can, for example, be a discussion about conversational rules or why one doesn't get acknowledgement for the work one has done. Still, the concept is not given a central role in the paper. One reason may be that it is defined quite narrowly. Discussions about collaborative strategies are, for instance, categorized as "management" and not as metacommunication.

In a school context, Sawyer (2004) claims that teachers must be able to metacommunicate in classroom discussions. The teacher will sometimes need to repeat the rules of effective discussion. Occasionally, students must be told that they are straying too far from the topic, that they are not discussing the correct topic, or that they are talking too much. At the same time he warns against too much metacommunication or too many frame-breaking moves. It can potentially disturb the collaborative construction of knowledge in the class. Managing just the right level of metacommunication is not easy. Each discussion will likely require its own unique degree of metacommunication. Effective teachers therefore need to have a full repertoire of metacommunicative techniques available when classroom discussions are viewed as improvisational and not scripted (Sawyer, 2004).

In the context of political research, Stromer-Galley (2007) develops a content analysis scheme to measure the quality of political deliberation in face-to-face and online groups. One of the four main codes in this scheme is metatalk. Another example is Dunnahoe (2008) who investigates metatalk related to sharing affection in friendships. In addition, the metacommunication concept is not only being linked to traditional conversations, but also to distance education (Demiray, Kurubacak \& Yuzer, 2012) and online communities (Lanamäki \& Päivärinta, 2009). For example, Lanamäki and Päivärinta (2009) emphasize that online communities generate new metacommunication types that refer to the whole community discussion. The online encyclopedia Wikipedia illustrates a communication environment where one can discuss rules for text production. Furthermore, in research on mass media and political communication, the concept is used to define the news media's discussion of the interplay between political public relations and political journalism (Esser, Reinemann \& Fan, 2001). Nevertheless, the main focus in this paper is on verbal metacommunication in face-to-face conversation.

\section{Review of research literature in English about the metacommunication concept.}

\subsection{The concept challenge}

The short review of the metacommunication concept in the prior section indicates that most definitions in research literature in English are short and seldom described in great detail. Still, a brief historical review of the metacommunication concept shows that the definitions have been evolving over time. One main characteristic seems to be that the conceptual complexity has increased. Wilmot (1980), for example, distinguishes between episodic and relational metacommunication which can potentially refer to three different time dimensions ("upcoming", "ongoing" or "past" communication). Baltzersen (2008) has also developed a similar definition. Inspired by the German sociologist Luhmann (1995), Baltzersen (2008) assumes that a metacommunicative utterance can always be defined 
according to the following three basic questions or dimensions: What, how and when do you metacommunicate?

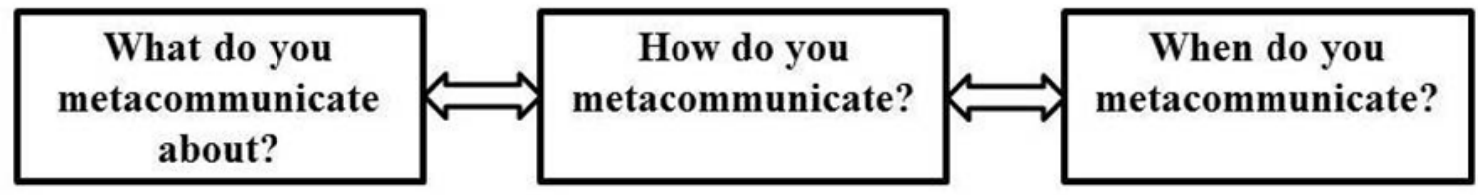

Figure 1. A metacommunication model

Every metacommunicative utterance can be analyzed according to all three dimensions. The dimensions will be explained in further detail in this section. Note that Baltzersen's (2008) definition was originally introduced in a Norwegian book with examples from a Norwegian context. Most of these examples were also only from a few different contexts, mainly professional dyadic conversation areas such as counseling and mentoring. In the following review of the concept, examples will be selected from a broader area of conversational contexts such as children's pretend play (Whitebread \& O'Sullivan, 2012), collaborative problem-solving among children (Wang, 1999) and classroom pedagogy (Sawyer, 2004). Despite this, a significant part of the examples and descriptions are from psychotherapy which is dyadic-orientated. The reason is that this seems to be the research context where the concept has been taken most in use. Relevant empirical research will also be included, although the number of studies is limited (Wang, 1999; Baltzersen, 2008). With the exception of research on children's play, there are few studies of how metacommunication is used in everyday conversations.

One main methodological challenge when trying to define the metacommunication concept is that it's quite easy to describe a few examples or some relevant components in a definition, but it's much harder to agree upon when something stops being metacommunication. Where do you draw the line? Researchers seem to have struggled in finding a clear-cut and coherent definition. One example is Stromer-Galley (2007) who categorizes metatalk as one of four main talking types. She claims to have used strict standards for creating coding schemes to ensure a valid and reliable coding process. Despite this, she writes that "process talk", one of the other main talking types, also might include aspects of metatalk. "Process talk" is defined as talk about the technical and deliberation processes. It can either be immediate to the discussion or related to the context of the discussion. It may include questions, agreement, disagreement and also metatalk. In addition, "social talk", the fourth main talking type, might be interpreted as a talk that includes some elements of metatalk. Stromer-Galley (2007) relates "social talk" to salutations, praise and apologies. The example of an apology, "I hope I haven't been too obnoxious." can also be interpreted as metatalk that focuses on a self-evaluation of the person's perceived group behavior. A statement of "praise" is illustrated by the following phrase: "You've been a good group." This statement can also be interpreted as metacommunication about the group relationship.

Researchers in psychotherapy seem to struggle with the same methodological challenges. Austin (2011) claims that metacommunicative statements usually don't fit neatly into the traditional content-based categorical rating system used to characterize therapist and client utterances. He mentions Hill et al. (1988), who classified nine content-based therapist "response modes" (i.e., interpretation, self-disclosure, paraphrase, approval, open question, confrontation, information, direct guidance and closed question). Instances of metacommunication might be present in several of these categories, such as "self-disclosure", "paraphrase", "approval", or "confrontation".

These two examples illustrate how difficult it is to define and categorize metacommunication in a consistent way. Baltzersen's (2008) definition is also limited in its exclusive focus on verbal metacommunication. Still, this definition is considered relevant for the research question in this paper. In the following section, this definition will be used as a framework to review several different examples and definitions of metacommunication.

\subsection{What do you metacommunicate about?}

The "What-dimension" suggests that you will always have to refer to some part of the communication when you metacommunicate. According to Baltzersen (2008), it's possible to divide the metacommunicative content into three main subcategories:

- Metacommunication about the conversational content.

- Metacommunication about the conversational relationship.

- Metacommunication about the use of conversational time. 
These categories are explained and discussed in more detail in the following section.

\subsubsection{Metacommunication about the conversational content}

One main option is to metacommunicate about the conversational content or the communicative episode (Baltzersen, 2008; Wilmot, 1980). This can be done in several different ways, and usually happens when a speaker is trying to manage or regulate the conversational content.

First, the speaker can explain intentions behind the conversational content. This seems to be a common strategy in everyday speech. In psychotherapy, Rennie (2006) suggests that talk about intentions can help both the speaker and the listener to better understand how they are communicating. According to my interpretation, he actually distinguishes between four different kinds of metacommunication related to explaining the conversational content.

Table 3. Illustration of different ways one can talk about the intentions behind the conversational content.

$$
\text { Talking about what the listener has said Talking about what the speaker has said }
$$

\begin{tabular}{lrl}
\hline Disclosing own & (1) The speaker discloses his experience \\
opinion about the & of what the listener has said (e.g., "When \\
conversation. & & I hear you say that you ... I think...").
\end{tabular}

Asking for others' opinion about the conversation.
(3) The speaker invites the listener to disclose his reasons behind what he is saying (e.g., "If you tell me why you are saying that...").
(2) The speaker discloses his reason for saying what is about to be said or has been said (e.g., "The reason I am telling you this is ...").

(4) The speaker invites the listener to comment on what the speaker has said (e.g., "I wonder what you are thinking about what I have said.").

As we can see from table 3, one can either disclose one's own opinion or ask for the other person's opinion. In addition, one can focus on what either the speaker or the listener has said. Rennie (2006) emphasizes that these different types of metacommunication can make the communication more transparent and the therapist less mystical.

Secondly, another kind of metacommunication is about the forthcoming conversational content. This "future-orientated" communication is a natural part of everyday language, but also an important part of professional conversations. For example, in psychotherapy this activity is sometimes labeled as creating a working alliance. Such alliances seek to create a joint involvement between the client and the therapist regarding what the problems are and what needs to be done to solve the problems. According to Bordin (1979), a good working alliance contains three components: agreement on specific tasks in the therapy, agreement on the goals of therapy, and possible strains in the patient-therapist relationship. Similar working alliances are recommended in a lot of other areas related to professional conversation, for instance teacher mentoring (Portner, 2005) and action research collaboration (Rosendahl \& Rönnerman, 2006). Nevertheless, these alliances are seldom labeled as metacommunication.

Finally, summarizing can be regarded as metacommunication about the conversational content. Usually one will still be talking about the same conversational topic, but this is done within a different communicative "frame". For example, the phrase "Let's summarize our discussion," can be regarded as an introductory framing of an extended period of metacommunication. The main goal is now to locate the essence of what has already been discussed. It is debatable whether all summaries, to some degree, are new interpretations of prior content, but the important issue here is the explicit attempt to identify the essential prior conversational content. In this way the content is not, in itself, metacommunication before it is verbalized as being part of the summary in the conversation.

Summarizing is usually recommended as a communicative strategy in professional conversations. It is usually seen as an important communication technique in active listening (Rogers, 1961). Summarizing can also be seen as an instructional strategy. Sawyer (2004) suggests that teachers metacommunicate when they summarize key points from the classroom discussion. Students are not usually able to do this by themselves. Teachers must be highly attentive at every moment of the discussion and have the difficult task of determining when a summary is necessary.

\subsubsection{Metacommunication about the conversational relationship}

The second main option is to metacommunicate about the conversational relationship (Baltzersen, 2008; Wilmot 1980). Usually this type of metacommunication is related to some kind of evaluation of the relationship between the persons interacting. This can be done in many different ways and also seems to be a natural part of everyday conversations, but it is perhaps most common in close relationships (Dunnahoe, 2008). Still, Stromer-Galley (2007) claims that metatalk that explicates disagreement is quite common in political group discussions (e.g. "I think we are 
disagreeing upon ....").

In addition, one can highlight one's own role or another person's role in the relationship (Baltzersen, 2008). This kind of metacommunication seems to be especially important in professional conversations such as psychotherapy (Safran, Muran, Samstag \& Stevens, 2002). Kiesler (1988) suggests that the client and the therapist should explore the interpersonal relationship together, which can be important for the client's view of him- or herself. The following example illustrates how a therapist can comment on the client's behavior in the conversational relationship: "I'm feeling kind of confused right now, and it seems to me that it had something to do with the way you kind of shut down and crossed your arms when we started talking about..." (Austin, 2011: 26). Notice that the therapist here not only mentions his own feelings ("confused"), but he also explicitly interprets the other person's body language. In this conversational context, it is often recommended that the therapist initiate a discussion about possible conflicts or disagreements in the relationship. McKay (2011) illustrates how a therapist explicitly encourages the client to talk openly about any relational concern. The therapist says: "(...) Let's make sure that as we move forward, we both bring up any concerns that we have. Are you up for that? Did this discussion help you, or did I scare you or upset you by bringing it up?" (McKay, 2011: 23). It is suggested that this kind of communication is crucial if the relationship in the psychotherapy is not good.

\subsubsection{Metacommunication about the use of conversational time}

A third main option is to metacommunicate about the use of conversational time. For example, persons talking to each other can discuss how much time they want to use to talk about a specific topic. Baltzersen (2008) suggests that this dimension should be included as a main metacommunicative subcategory even though this is not usual in most definitions. His argument is that a discussion around conversational time-use is closely linked to a discussion of the conversational "frame".

\subsection{How do you metacommunicate?}

The "How-dimension" suggests that a metacommunicative utterance will always say something about how people relate to each other. For example, body language and how we use our voice will also be of importance when we metacommunicate. In a conversation, people will also metacommunicate to a different degree. In this regard, Baltzersen (2008) distinguishes between monological and dialogical metacommunication.

Monological metacommunication refers to a situation where only one person is metacommunicating. This kind of metacommunication may have either a positive or a negative impact on the conversation. If the monologue is a negative evaluation of the conversational relationship, this may potentially lead to a conflict. Rossiter Jr. (1974) claims that metacommunication formulated as direct accusations often evokes some kind of defensive response such as denial. This may happen if somebody is accused of dominating the conversation too much. A more constructive strategy would be to comment more descriptively on the other's behavior (e.g., "You have now interrupted other people three times in a row.") Even though these two examples are different, they both illustrate monological metacommunication because only one person is metacommunicating.

Oppositely, dialogical metacommunication indicates that all persons in the conversation are metacommunicating. This is usually a recommended strategy in professional conversation, although the activity is seldom labeled this way. In psychotherapy, Villard and Whipple (1976) claim that metacommunication should be used to support the development of an equal relationship between therapist and client, rather than establishing the superiority of the therapist. Similarly, Bordin (1979) emphasizes that both therapist and client should agree upon the communication norms in the therapy sessions. According to Austin (2011), most metacommunication guidelines today seem to encourage a sense of mutuality, promoting a feeling of "being in the same boat". It is suggested that conversational norms should always be open for possible modification or rejection by the client.

\subsection{When are you metacommunicating?}

The "When-dimension" suggests that a metacommunicative utterance will always take place at a specific time, whether it is at the beginning, the middle or the end of a conversation. This specific point in time will also influence whether one talks about the past or future conversation. In addition, it's possible to metacommunicate about the ongoing "here-and-now" conversation, for example, by explaining the intentions behind what was recently said or by posing clarifying questions (Baltzersen, 2008). Other definitions of metacommunication seem to include only a few of these time dimensions. Wang (1999: 4) defines metacommunication as any statement about what has just been said or would be said. Metacommunication about the past conversation within an extended time period is not included in the definition. Stromer-Galley (2007: 9) defines metatalk "as talk about the talk. It is talk that assesses what has transpired or is transpiring in the interaction, either as a group, or between individuals or to clarify meaning 
- one's own or someone else's". In this example, the forthcoming conversation is neglected. In the following section, aspects of the "When-dimension" will be discussed in further detail.

\subsubsection{Metacommunication as part of the ongoing "here-and-now" conversation}

There seem to be several examples in the literature of metacommunicative utterances that occur as a need in the immediate situation and are used to instantly regulate the conversation. Bateson (1972) emphasized that in daily language use, there is a constant interchange of metacommunicative messages such as "What do you mean?" or "Are you kidding me?" It's sometimes necessary to make such comments in order to find out what people are really saying. One common strategy seems to be to ask for clarification of something that has just been said (e.g. "Can you repeat what you just said?"). The primary intention is to reduce confusion and try to get more information about what somebody else thinks. A student may, for instance, ask the teacher to explain a problem in more detail. In political discussions in small groups, Stromer-Galley (2007) located two different types of clarification. There is the clarification of the speaker's own prior opinion or fact statement ("What I'm trying to say is...") or some other speaker's opinion ("Sally, so, what you're saying is...").

Interestingly, Bateson (1972) considered this kind of metacommunication as essential for successful social interaction. In a research study, Wang (1999) found that children who used this kind of metacommunication when they were collaborating solved problems more efficiently. Pairs of children were given instructions to move a robot in order to achieve a goal. The "Witness" gave the instructions, while the "Operator" did the task. The pairs had to collaborate, and when failures occurred, children would need to metacommunicate in order to solve these problems:

- "Witness": Move up!

- "Operator": What did you say? (Metacommunication)

- "Witness": Put up the hand. (Wang 1999:6)

Wang (1999) found that this kind of metacommunication was very important in order to get more information from the "Witness" and solve the problem. A variety of metacommunicative strategies was used, such as paraphrasing, repeating something said earlier, talking about time use, commenting on language use or regulating others by telling them not to continue to speak. Children that metacommunicated more frequently received a more accurate description of the instructions. They also learned more about the other child's opinion of the task. Extensive metacommunication in the beginning also seemed to make the later phases of the problem-solving process more effective. Children who developed their metacommunicative competence were also able to formulate better and more precise instructions when solving new problems.

\subsubsection{Metacommunication within an extended time frame}

Metacommunication within an extended time frame is related to either a past or future conversation which goes beyond the immediate communicative situation. This kind of metacommunication is often considered important in professional conversations, which can endure for a longer predefined time period. For example, in the beginning of a professional collaboration, it is often recommended that the partners establish a working alliance. In psychotherapy, such an alliance is considered to be one of the best and most consistent predictors of successful adult psychotherapy (Austin, 2011; Bordin, 1979; Kiesler, 1988; McKay, 2011).

\section{Implications for supervision in higher education.}

The initial research question was: What kind of metacommunication is important to create good supervision in higher education? The review of the research literature gives an indication of the broad range of different types of metacommunication that might have a positive effect on communication. Based on these findings, I discuss whether two separate types of metacommunication should be considered as important communicative strategies in supervision in higher education.

\subsection{Metacommunication as part of a transparent communication style in supervision}

Several of the different kinds of metacommunication in the review seem to indicate the importance of an open and transparent communication style. Some relevant types of metacommunication are questions of clarification and paraphrasing. Students should feel that they can interrupt the supervisor in the ongoing conversation with questions such as "What do you mean when you are saying that?" This might both reduce confusion and improve the understanding of the academic content. Explaining intentions behind the conversational content might also help both supervisor and student to better understand communicative messages in the supervision.

Although many of these strategies might already be in use, because of limited empirical research we don't know to 
what degree this communication style is used by supervisors in higher education. It seems that this kind of metacommunication is closely related to what one could label as a "contractual" style in supervision (Acker, Hill \& Black, 1994; Deuchar, 2008; Taylor \& Beasley, 2005). Taylor and Beasley (2005) distinguish between four different supervision styles: Firstly, the "laisser-faire" style assumes that students can manage all of their work themselves. Secondly, the "pastoral" style presupposes that the student can manage the project, but will need personal support from the supervisor. Thirdly, the "directorial" style expects that the student will need help in managing their project, but it's not necessary to give personal support. Finally, the "contractual" style assumes that student and supervisor need to discuss the degree of support and find the best solution together.

The "contractual" style seems to presuppose a large degree of metacommunication in the supervision process. Deuchar (2008) found that students value a "negotiated order" model of supervision based on open communication and an honest exchange of opinions. One important reason is the usual lack of congruence between the style of supervision and the candidate's needs. Often tensions may arise because supervisors expect more student autonomy than the students themselves expect. According to Wichmann-Hansen et al. (2012), major problems in supervision often begin as small problems which are unsolved and not addressed. The supervisor should therefore encourage students to initiate a discussion if problems arise, however small they may seem. It is likely that questions of clarification as part of the ongoing "here-and-now" conversation will be an important part of this communication style. Deuchar (2008) also emphasizes that the supervisory relationship should be open and fluid. When identities are negotiable, expectations between supervisor and student are open to change throughout the supervision process. This may require that both the student and supervisor metacommunicate about conversational content and explain their intentions in the ongoing conversation.

\subsection{Metacommunication about the collaboration period in supervision}

The review also shows that metacommunication plays an important part in the strategic planning of a conversation. The establishment of a working alliance is recommended within psychotherapy and also seems to be of importance in professional mentoring and supervision in higher education. For example, the survey about metacommunication in section 1 indicated the importance of early-phase metacommunication. Several researchers in higher education also emphasize the importance of discussing roles and expectations in the beginning phase of the doctoral supervision process. Student and supervisor should talk about their expectations before they start working together (Burns, Lamm \& Lewis, 1999; Halse \& Malfroy, 2010; Wichmann-Hansen et al., 2012). Halse and Malfroy (2010) recommend the establishment of a "learning alliance" which is defined as an agreement between supervisor and student that specifies common goals. Based on their study of supervisors, they identified the central features in the learning alliance to be mutual respect, flexible adjustment to the student's needs, clear communication and explicit strategies for progressing towards a doctoral degree. They actually describe this agreement as similar to the collaborative "therapeutic alliance" between a patient and a clinician which was presented as an example of dialogic metacommunication in the review (section 3.3). This alliance is to a larger degree based on responsibility and a personal relationship rather than only being a set of rights and principles. Similarly, Wichmann-Hansen et al. (2012) recommend the establishment of a $\mathrm{PhD}$ plan where the student and the supervisor should make their expectations clear. A plan should include components such as a timetable, an agreement about the form of supervision and plans for the project. These researchers also present several recommendations which could be interpreted as different types of metacommunication.

Firstly, Wichmann-Hansen et al. (2012) suggest that students should explain what kind of feedback they want when they send a text to their supervisor. One important reason is that students seem to have different writing styles. Some students write many drafts, while others write finished sections right away (Galbraith \& Torrance, 2004). Students and supervisors should therefore agree upon how they want to work with manuscripts and drafts (Wichmann-Hansen et al., 2012). This communication can be regarded as metacommunication about the conversational content. Students and supervisors are here encouraged to discuss how they want to organize the academic discussion in the supervision process. According to Sinclair (2004), text production seems to be very important from the beginning of the supervision process. Good supervisors seem to encourage candidates to work on more than one task at a time so they always have something they can work with.

Secondly, Wichmann-Hansen et al. (2012) suggest that student and supervisor should discuss the need for personal contact and informal exchange of ideas. This may be interpreted as an example of metacommunication about the conversational relationship where the researchers recommend an open disucssion about the degree of closeness in the relationship. It would be interesting to do more studies on this topic, since the supervisory relationship is usually considered as very important for the success of the PhD study (Delamont, Atkinson \& Parry 2004; Phillips \& Pugh, 
2005). On the other side, one can discuss whether this kind of metacommunication is always appropriate in higher education. It is not clear if it is effective to try and explicitly regulate the relationship in all kinds of professional conversations. Some kinds of metacommunication may be inappropriate (e.g. "I hate the way you talk to me.") while other examples may be more appropriate in a formal learning environment (e.g. "I want everybody in the group to support each other; how do we achieve this?"). There are also examples of thesis supervisors who start the supervision process by explicitly telling the students that they don't want to talk about personal issues (Baltzersen, 2008). Another question is whether one can talk about this in an effective way in the beginning of the supervision process. Usually mutual trust is considered as a very important factor in a good supervisory relationship because it will be easier for students to approach their supervisors. Still, we don't know if one can develop trust by talking about it (Sinclair, 2004). There seem to be few studies of natural language or discourse that explicitly address this topic.

Thirdly, they recommend that one should discuss whether the supervisor wants to be contacted regularly or if the student should decide when help is needed (Wichmann-Hansen et al., 2012). This can be interpreted as metacommunication about the use of conversational time in the supervision process. This kind of metacommunication seems to be important in order to move from a "hands off" to a "hands on" approach. According to Sinclair (2004), a "hands off" approach leaves students largely to themselves. This is usually not recommended unless the student is very independent and knowledgeable. A "hands on" approach describes a consistent relationship which requires more meetings and frequent contact between the supervisor and the student. An important basis is the achievement of an early and lasting agreement about regular meeting time.

In addition, the study presented in section 1 suggested that students who regularly metacommunicate experience the communication as better. Several researchers in higher education also recommend that the working alliance and the supervisory relationship may need to be renegotiated at various times during the supervision period (Burns et al.,1999; Parry \& Hayden, 1994; Wichmann-Hansen et al., 2012). Wichmann-Hansen et al. (2012) suggest regular "process supervision meetings" to ensure sufficient follow-up on student progress in order to follow up progression in a sufficient way. This includes issues such as students' writing skills, time management and goal realism which supervisors can sometimes have a tendency to neglect (Wichmann-Hansen et al., 2012: 58). This can be interpreted as an approach which emphasizes dialogic metacommunication.

\subsection{Suggestions for future research}

Future research should try to explain the specific metacommunicative mechanisms that regulate good supervision in more detail. It might be fruitful to explore how planned and more spontaneous metadiscourse interplay in high quality conversations. This will require discourse data from higher education. Metacommunication may also be of importance in classroom conversations, group work and peer tutoring (Falchikov, 2012; Scardamalia \& Bereiter, 2006). One purpose of metacommunication would be to improve student achievement while letting them be in charge of their own learning process. Knowledge on how this specific type of verbal communication supports these processes might be important in all fields where one wishes people to work efficiently, but also independently.

\section{References}

Acker, S., Hill, T., \& Black, E. (1994). Thesis supervision in the social sciences: Managed or negotiated? Higher Education, 28 (4), 483-498. http://dx.doi.org/10.1007/BF01383939

Austin, T. M. (2011). A Task Analysis of Metacommunication in Time-Limited Dynamic Psychotherapy. (Doctoral dissertation, Antioch [Online] Available: http://etd.ohiolink.edu/view.cgi?acc_num=antioch1305028242

Baltzersen, R. K. (2008). A samtale om samtalen. Veiledning og metakommunikasjon. [Talking about the talk. Mentoring and metacommunication]. Bergen: Fagbokforlaget.

Bateson, G. (1951). Information and codification: a philosophical approach. In J. Ruesch \& G. Bateson (Eds.), Communication: the social matrix of psychiatry (pp. 168-211). New York: Norton.

Bateson, G. (1972). Steps to an Ecology of Mind. New York: Ballantine. http://dx.doi.org/10.7208/chicago/9780226924601.001.0001

Bateson, G. (1976). A theory of play and fantasy. In B. Sutton-Smith (Ed.), The psychology of play (pp. 39-51). New York: Arno Press.Beam, B. D. (2006). Therapists' Metacommunication Strategies: A Qualitative Analysis. ProQuest.

Bordin, E. (1979). The generalizability of the psychoanalytic concept of the working alliance. Psychotherapy: Theory, 
Research and Practice, 16, 252-260. http://dx.doi.org/10.1037/h0085885

Brems, C. (2001). Basic skills in psychotherapy and counseling. Belmont, CA: Brooks Cole.

Burns, R., Lamm, R., \& Lewis, R. (1999). Orientations to higher degree supervision: A study of supervisors and students in education. Supervision of postgraduate research in education, 55-74.

Cazden, C. B. (2001). Classroom discourse: The language of teaching and learning. Portsmouth, NH: Heinemann.

Crisp, G., \& Cruz, I. (2009). Mentoring college students: A critical review of the literature between 1990 and 2007. Research in Higher Education, 50(6), 525-545. http://dx.doi.org/10.1007/s11162-009-9130-2

Cuban, L. (2001). Oversold and Underused: Computers in the Classroom. Mass.: Harvard University Press.

Delamont, S., Atkinson, P., \& Parry, O. (2004). Supervising the doctorate: A guide to success. McGraw-Hill International.

Demiray, U., Kurubacak, G., \& Yuzer, T. V. (2012). Meta-Communication for Reflective Online Conversations: Models for Distance Education. Hershey: IGI Global. http://dx.doi.org/10.4018/978-1-61350-071-2

Deuchar, R. (2008). Facilitator, director or critical friend?: contradiction and congruence in doctoral supervision styles. Teaching in Higher Education, 13(4), 489-500. http://dx.doi.org/10.1080/13562510802193905

Dillenbourg, P., \& Traum, D. (2006). Sharing Solutions: Persistence and Grounding in Multimodal Collaborative Problem Solving. Journal of the Learning Sciences, 15(1), 121-151. http://dx.doi.org/10.1207/s15327809j1s1501_9

Doehring, P. (1993). Metacommunication of children between five and ten years of age as a function of play context (Doctoral dissertation, Concordia University). [Online] Available: http://spectrum.library.concordia.ca/3673/

Dunnahoe, R. E. (2008). Meta-communication: An Investigation of Talk about Sharing Affection in Geographically Close and Long-distance Friendships. ProQuest.

Dysthe, O., Samara, A., \& Westrheim, K. (2006). Multivoiced supervision of Master's students: a case study of alternative supervision practices in higher education. Studies in Higher Education, 31(03), 299-318. http://dx.doi.org/10.1080/03075070600680562

Esser, F., Reinemann, C., \& Fan, D. (2001). Spin Doctors in the United States, Great Britain, and Germany Metacommunication about Media Manipulation. The Harvard International Journal of Press/Politics, 6(1), 16-45. http://dx.doi.org/10.1177/1081180X01006001003

Falchikov, N. (2012). Learning together: Peer tutoring in higher education. London: Routledge. http://dx.doi.org/10.4324/9780203451496

Falkfjell, L. \& Smeby, J.C. (1999). Veien gjennom hovedfaget. [The road through the master programme]. Oslo: NIFU skriftserie.

Galbraith, D., \& Torrance, M. (2004). Revision in the context of different drafting strategies. In L. Allal, L. Chanquoy, \& P. Largy (Eds.), Revision: Cognitive and Instructional Processes (pp. 63-85). Amsterdam: Kluwer Academic Publishers. http://dx.doi.org/10.1007/978-94-007-1048-1_5

Halse, C., \& Malfroy, J. (2010). Retheorizing doctoral supervision as professional work. Studies in Higher Education, 35(1), 79-92. http://dx.doi.org/10.1080/03075070902906798

Halliday-Scher, K., Urberg, K. A., \& Kaplan-Estrin, M. (1995). Learning to pretend: Preschoolers' use of meta-communication in sociodramatic play. International Journal of Behavioral Development, 18(3), 451-461.

Hill, C. E., Helms, J. E., Tichenor, V., Spiegel, S. B., O’Grady, K. E., \& Perry, E. S. (1988). Effects of therapist response modes in brief psychotherapy. Journal of Counseling Psychology, 35(3), 222-233. http://dx.doi.org/10.1037//0022-0167.35.3.222

Hobson, A. J., Ashby, P., Malderez, A., \& Tomlinson, P. D. (2009). Mentoring beginning teachers: What we know and what we don't. Teaching and Teacher Education, 25(1), 207-216. http://dx.doi.org/10.1016/j.tate.2008.09.001

Holmberg, L. (2006). Coach, consultant or mother: Supervisors' views on quality in the supervision of bachelor theses. Quality in Higher Education, 12(2), 207-216. http://dx.doi.org/10.1080/13538320600916833

Johnson, B. W. (2006). On being a mentor: A guide for higher education faculty. Mahwah, NJ: Lawrence Erlbaum Associates. 
Kiesler, D. J. (1988). Therapeutic metacommunication: Therapist impact disclosure as feedback in psychotherapy. Palo Alto, CA: Consulting Psychologists Press.

Lanamäki, A., \& Päivärinta, T. (2009). Metacommunication Patterns in Online Communities. In A. A. Ozok \& P. Zaphiris (Eds.), Online Communities and Social Computing. Third International Conference, OCSC 2009, Held as Part of HCI International 2009, San Diego, CA, USA, July 19-24, 2009. Proceedings. (Vol. 5621, pp. 236-245). Berlin Heidelberg: Springer-Verlag. http://dx.doi.org/10.1007/978-3-642-02774-1_26

Lee, A. (2008). How are doctoral students supervised? Concepts of doctoral research supervision. Studies in Higher Education, 33(3), 267-281. http://dx.doi.org/10.1080/03075070802049202

Luhmann, N. (1995). Social Systems. Stanford: Stanford University Press.

McCallin, A., \& Nayar, S. (2012). Postgraduate research supervision: a critical review of current practice. Teaching in Higher Education, 17(1), 63-74. http://dx.doi.org/10.1080/13562517.2011.590979

McKay, T. L. (2011). The Effects Of Meta-Communication Training On Therapeutic Process And Outcome At A University Counseling Center. (Doctoral dissertation.) Retrieved from Wayne State University Dissertations. (Paper 200) [Online] Available: http://search.proquest.com/docview/854330987

Nakamura, J., Shernoff, D. J., \& Hooker, C. H. (2009). Good mentoring: Fostering excellent practice in higher education. Jossey-Bass.

Parry, S. \& Hayden, M. (1994). Supervising Higher Degree Research Students. Canberra: Australian Government Publishing Service.

Phillips, E., \& Pugh, D. S. (2005). How to get a PhD: a handbook for students and their supervisors. Maidenhead: Open University Press.

Portner, H. (2005). Teacher Mentoring and Induction: The State of the Art and Beyond. Thousand Oaks, CA: Corwin Press.

Rawlins, W. K. (1987). Gregory Bateson and the composition of human communication. Research on Language \& Social Interaction, 20(1-4), 53-77. http://dx.doi.org/10.1080/08351818709389275

Rennie, D. L. (2006). Radical Reflexivity: Rationale for an experiential person-centered approach to counseling and psychotherapy. Person-Centered \& Experiential Psychotherapies, 5(2), 114-126.

Rogers, C. R. (1961). On becoming a person: a therapist's view of psychotherapy. London: Constable.

Rosendahl, B. L., \& Rönnerman, K. (2006). Facilitating school improvement: the problematic relationship between researchers and practitioners. Journal of In-service Education, 32(4), 497-509. http://dx.doi.org/10.1080/13674580601024457

Rossiter Jr, C. M. (1974). Instruction in metacommunication. Communication Studies, 25(1), 36-42. http://dx.doi.org/10.1080/10510977409367766

Safran, J. D., Muran, J. C., Samstag, L. W., \& Stevens, C. (2002). Repairing alliance ruptures. In J. C. Norcross (Ed.), Psychotherapy relationships that work: Therapist contributions and responsiveness to patients (pp. 235-254). New York, NY: Oxford University. http://dx.doi.org/10.1093/acprof:oso/9780199737208.003.0011

Safran, J.D., \& Muran, J.C. (2003). Negotiating the therapeutic alliance: A relational treatment guide. New York: Guilford Press.

Sambrook, S., Stewart, J., \& Roberts, C. (2008). Doctoral supervision... a view from above, below and the middle! Journal of Further and Higher Education, 32(1), 71-84. http://dx.doi.org/10.1080/03098770701781473

Sawyer, R.K. (1997). Pretend play as improvisation: Conversation in the preschool classroom. Hillsdale, NJ: Lawrence Erlbaum.

Sawyer, R.K. (2003). Levels of analysis in pretend play discourse: Metacommunication in conversational routine. In D. Lytle (Ed.), Play and educational theory and practice (pp. 137-157). Westport, CT: Prager.

Sawyer, R. K. (2004). Improvised lessons: Collaborative discussion in the constructivist classroom. Teaching Education, 15(2), 189-201. http://dx.doi.org/10.1080/1047621042000213610

Scardamalia, M., \& Bereiter, C. (2006). Knowledge building: Theory, pedagogy, and technology. In K. Sawyer (Ed.), Cambridge handbook of the learning sciences (pp. 97-118). Cambridge, UK: Cambridge University Press http://dx.doi.org/10.1017/CBO9780511816833.008 
Schalk, R., \& Roe, R. E. (2007). Towards a dynamic model of the psychological contract. Journal for the Theory of Social Behaviour, 37(2), 167-182. http://dx.doi.org/10.1111/j.1468-5914.2007.00330.x

Sinclair, M. (2004). The pedagogy of good PhD supervision: A national cross-disciplinary investigation of PhD supervision. Canberra: Department of Education, Science and Training.

Stromer-Galley, J. (2007). Measuring deliberation's content: A coding scheme. Journal of Public Deliberation, 3(1), 12.

Taylor, S., \& Beasley, N. (2005). A handbook for doctoral supervisors. New York, NY : Routledge Falmer. http://dx.doi.org/10.4324/9780203415740

Villard, K. L., \& Whipple, L. J. (1976). Beginnings in relational communication. New York: John Wiley \& Sons.

Walker, G. E., Golde, C. M., Jones, L., Bueschel, A. C., \& Hutchings, P. (2008). The formation of scholars: Rethinking doctoral education for the 21st century. San Francisco: Jossey-Bass.

Wang, Y. (1999). Metacommunication and problem solving in a collaborative task of young children (Doctoral dissertation) School of Education, University of Massachusetts Amherst. [Online] Available: http://scholarworks.umass.edu/dissertations/AAI9932354!

Watzlawick, P., Beavin, P., \& Jackson, D.D. (1967). Pragmatics of human communication. A study of interactional patterns, pathologies and paradoxes. New York: Norton.

Whitebread, D., \& O'Sullivan, L. (2012). Preschool children's social pretend play: supporting the development of metacommunication, metacognition and self-regulation. International Journal of Play, 1(2), 197-213. http://dx.doi.org/10.1080/21594937.2012.693384

Whitelock, D., Faulkner, D., \& Miell, D. (2008). Promoting creativity in PhD supervision: Tensions and dilemmas. Thinking Skills and Creativity, 3(2), 143-153. http://dx.doi.org/10.1016/j.tsc.2008.04.001

Wichmann-Hansen, G.M., Bach, L.W., Eika, B. \& Mulvany, M.J. (2012). Successful PhD supervision: a two-way process. In Castano, M.A.R.B. \& Guner-Akdogan, G. (Eds.) Mentoring in Academia and Industry: Researching, Teaching, and Learning Triangle, 10 (2), 55-64. New York: Springer. http://dx.doi.org/10.1007/978-1-4614-0568-9_5

Wilmot, W. W. (1980). Metacommunication: A re-examination and extension. In: Nimmo, D. (ed.) Communication yearbook, 4, 61-69. New Brunswick: Transaction Publishers.

\section{Notes}

Note 1. In some research literature mentoring is used in a similar way to supervision (Johnson, 2006; Crisp \& Cruz, 2009; Nakamura, Shernoff, \& Hooker, 2009). Mentoring is also a common concept in teacher education (Hobson, Ashby, Malderez, \& Tomlinson,2009).

Note 2. Students from several major academic areas (humanities, natural science and social science) were represented in the survey. 